\title{
Development of a New Hybrid Between Prunus tomentosa Thunb. and Prunus salicina Lindl.
}

\author{
Qijing Zhang and Dajun Gu' \\ Liaoning Institute of Pomology, Xiongyue, Liaoning 115214, P.R. China
}

Additional index words. hybrid, Prunus tomentosa, Prunus salicina, characterization

\begin{abstract}
An interspecific hybrid between Prunus tomentosa and $P$. salicina was produced through controlled pollination and confirmed by comparison of morphological characters and DNA markers. Morphological traits were intermediate between the two parents and fruit are much larger than that of $P$. tomentosa. Trees grafted on $P$. tomentosa rootstock are compact, cold hardy, precocious, and productive. It is new and potentially useful stone fruit germplasm for commercial production and further breeding in Prunus.
\end{abstract}

Prunus tomentosa Thunb. $(2 n=16)$ and $P$. salicina Lindl. $(2 n=16)$ of the family Rosaceae belong to different subgenera. Prunus tomentosa is in the subgenus Cerasus, while P. salicina is in the subgenus Prunophora (Ingram, 1948; Rehder, 1940). Both species are native to China and have been cultivated for over 2000 years (Yü and $\mathrm{Li}$, 1986). Prunus tomentosa is a cold tolerant species and can endure winter temperatures as low as $-40{ }^{\circ} \mathrm{C}$. It is self-pollinated with fruits resistant to rain cracking and ripening synchronously (Zhang et al., 2008). Small fruit size $(0.4-2.85 \mathrm{~g})$ has been one of the major factors limiting its development. Prunus salicina is one of the important commercial stone fruits both in China and internationally and is valued for its large fruit size (5-90 g) and good quality. However, most cultivars require pollination trees to get good harvest (Zhang, 1990).

Hybridization between species in Prunus is possible and a number of useful interspecific hybrids have been reported (Burbank, 1914; Felipe, 2009; Shoferistov, 1988). Some hybrids have been widely used in fruit production either as scion cultivars or rootstocks. A hybrid rootstock for peach was derived from a cross of $P$. tomentosa and P. cerasifera (Warner, 1998). However, hybridization between $P$. tomentosa and $P$. salicina has not been reported previously. Hybridization of these two species could potentially combine the cold hardiness and self-compatibility of $P$. tomentosa with large fruit size of $P$. salicina and broaden the genetic base for further breeding within this genus.

The objective of this research was to characterize the morphology of the hybrid and both parents and to validate the hybridity using molecular markers. This article reports the first breeding and validation of an interspecific hybrid between $P$. tomentosa and $P$. salicina.

Received for publication 17 Oct. 2014. Accepted for publication 2 Mar. 2015.

${ }^{1}$ To whom reprint requests should be addressed; e-mail dajungu@163.com.

\section{Materials and Methods}

Breeding process. The hybrid was selected from a group of seedlings from a controlled cross between $P$. tomentosa (female parent) and $P$. salicina (male parent) in May 1986 in Shangzhi County, Heilongjiang Province, China $\left(45^{\circ} 14^{\prime} \mathrm{N}, 127^{\circ} 58^{\prime} \mathrm{E}\right)$. Female parents were 7 - to 10 -year-old trees of $P$. tomentosa with large fruit size $(2.3 \mathrm{~g}$ average) and were selected locally. The male parent was a cold hardy cultivar of $P$. salicina ('Xiaobenli') with fruit weight ranging from 40 to $60 \mathrm{~g}$. One tree (putative hybrid) was distinct in showing larger fruit that ripened about $15 \mathrm{~d}$ later than other progeny. An individual plant selection was made by $\mathrm{Mr}$. Jinsheng Liu in 1990, who also conducted the evaluation of the hybrid for 6 years. Scientific evaluation and description were carried out in the Liaoning Institute of Pomology and the Berry Institute of Heilongjiang province.

Morphological identification. Characterization of vegetative traits and fruits was based on almond descriptors developed by the International Plant Genetic Resources Institute (IPGRI) (Gulcan, 1985) as given in Table 1 and Figures 1-4.

Molecular confirmation. Six DNA samples were prepared, two from P. tomentosa, two from accessions ('Xiaobenli' and 'Longyuanquli') of $P$. salicina, and two from the putative hybrid. Genomic DNA extraction from young expanded terminal leaves was following (Zhang et al., 2008). Extracted genomic DNA was PCR-amplified using one pairs of microsatellite primers (UDP96003) selected from previous report (Zhang et al., 2008). The PCR program included an initial denaturation step at $94{ }^{\circ} \mathrm{C}$ for $4 \mathrm{~min}$, followed by 29 cycles of $45 \mathrm{~s}$ at $94{ }^{\circ} \mathrm{C}, 45 \mathrm{~s}$ at 59 , and $45 \mathrm{~s}$ at $72{ }^{\circ} \mathrm{C}$. The amplification products were loaded on a $6 \%$ nondenatured polyacrylamide gel and the gel was stained with silver nitrate.

\section{Results and Discussion}

Morphological difference. Characteristics of the progeny clearly demonstrated hybrid origin (Table 1). Flowers showed some

Table 1. Morphological comparison of $P$. tomentosa (female) and $P$. salicina (male) with the hybrid.

\begin{tabular}{llll}
\hline Characteristics & \multicolumn{1}{c}{ P. tomentosa } & \multicolumn{1}{c}{ Hybrid } & \multicolumn{1}{c}{ P. salicina } \\
\hline Flower diameter & $18-25 \mathrm{~mm}$ & Flowers & \\
Flower color & Light pink & $16-23 \mathrm{~mm}$ & $16-24 \mathrm{~mm}$ \\
Petal trait & Crumpled & White & White \\
Sepal length & $3-6 \mathrm{~mm}$ & Flat & Flat \\
Sepal color & Red & $2.5-4 \mathrm{~mm}$ & $1.5-3 \mathrm{~mm}$ \\
Stigma color & White & Green & Green \\
Hypanthium shape & Cylindrical & White & Light yellow \\
Hypanthium length & $4-6 \mathrm{~mm}$ & Cylindrical & Bell \\
Pedicel length & $1-1.8 \mathrm{~mm}$ & $2-3 \mathrm{~mm}$ & $1.5-2.5 \mathrm{~mm}$ \\
& & $4-7 \mathrm{~mm}$ & $11-16 \mathrm{~mm}$
\end{tabular}

\begin{tabular}{llll} 
& & \multicolumn{2}{c}{ Fruits } \\
Fruit color & Red & Red & Light red \\
Fruit diameter & $9-12 \mathrm{~mm}$ & $16-20 \mathrm{~mm}$ & $23-27 \mathrm{~mm}$ \\
Surface of fruit & Densely pubescent & Lightly pubescent & Glabrous \\
Wax powders & No & Thin & Thick \\
Stone shape & Elliptical & Round & Round \\
Stone exterior & Smooth & Furrow & Furrow \\
Stone size & Small & Middle & Large \\
& & & \\
Leaf length & & Leaves & \\
Leaf width & $30-50 \mathrm{~mm}$ & $30-50 \mathrm{~mm}$ & $40-65 \mathrm{~mm}$ \\
Leaf shape & $20-25 \mathrm{~mm}$ & $20-25 \mathrm{~mm}$ & $18-25 \mathrm{~mm}$ \\
Tip shape & Elliptical & Elliptical & Narrow-elliptical \\
Leaf margin & Acuminate & Acuminate & Apiculate \\
Petiole length & Deep serrate & Serrate & Serrulate \\
Surface of leaf & $2-5 \mathrm{~mm}$ & $6-9 \mathrm{~mm}$ & $10-15 \mathrm{~mm}$ \\
& Rough-veined and & Veined and lightly & Glabrous \\
& densely pubescent & pubescent & \\
Internode length & & & \\
Stipule number & $8-15 \mathrm{~mm}$ & Young shoots & \\
Surface of young shoot & $3-6$ & $20-30 \mathrm{~mm}$ & $20-35 \mathrm{~mm}$ \\
\hline
\end{tabular}

Values for progeny are based on eight individual hybrid trees. 


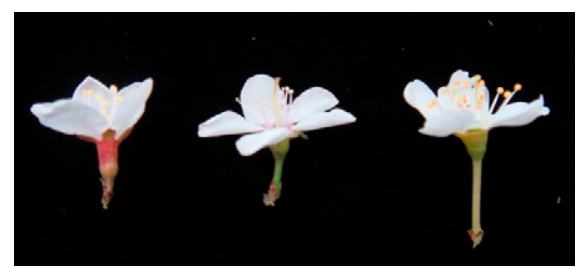

Fig. 1. Comparison of flowers between parents and interspecific hybrid. Left: $P$. tomentosa. Middle: hybrid. Right: $P$. salicina. The length of hypanthium and pedicel of the hybrid flower are intermediate between the parents.

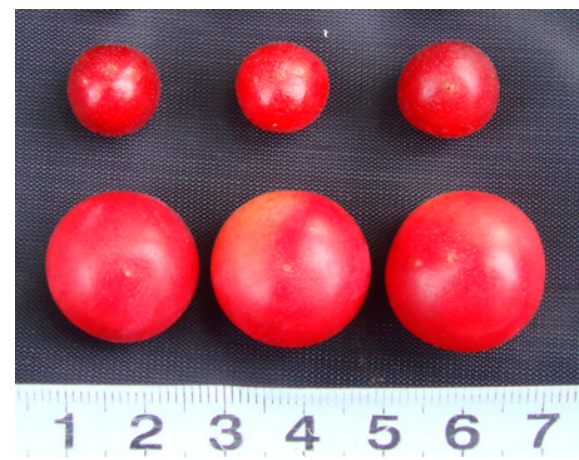

Fig. 2. Comparison of fruit of $P$. tomentosa and its hybrid. Upper: P. tomentosa. Lower: hybrid. Fruits of hybrid are much larger than fruits of $P$. tomentosa, although they are not completely mature compared with the tomentosa cherries.

characteristics of the paternal parent with smooth white petals (RHS NN155C) and greenish sepals (RHS 128D), and hypanthiums [Royal Horticulture Society (RHS), 2007], while the maternal parent has crumpled light pink (RHS N62D) petals and red (RHS 37D) sepals, and hypanthiums. Length of hypanthiums $(2-3 \mathrm{~mm})$ was intermediate between the two parents, being shorter than $P$. tomentosa $(4-6 \mathrm{~mm})$ and longer than $P$. salicina $(1.5-2.5 \mathrm{~mm})$. The hybrid had longer pedicels (4-7 $\mathrm{mm})$ than $P$. tomentosa $(1-1.8$ $\mathrm{mm})$, but were shorter than $P$. salicina (11$16 \mathrm{~mm}$ ) (Figs. 1 and 3). Leaves of the hybrid were more similar to $P$. tomentosa, but were less rugose and showed less pubescence. Petiole length $(6-9 \mathrm{~mm})$ was intermediate between the two parents. Stipules were common in $P$. tomentosa, whereas they were rare in the hybrid, similar to $P$. salicina. Leaf margins of the hybrid were also intermediate between the deep serrate leaf margins of $P$. tomentosa and the serrulate margins of $P$. salicina. Vegetative and flower buds of the hybrid were clustered in three at each node and lacked pubescence similar to $P$. salicina. Hybrid fruit was red (RHS 45B) in color when ripe (Figs. 2 and 3), similar to $P$. tomentosa cherries and darker than the light red (RHS 45D) fruit color of $P$. salicina. Fruit skin had less wax than that of fruit of $P$. salicina and considerably less pubescence than fruit of $P$. tomentosa. Flesh of ripe fruit was light red (RHS N30B), lighter than that of $P$. tomentosa (RHS 40C), while it was

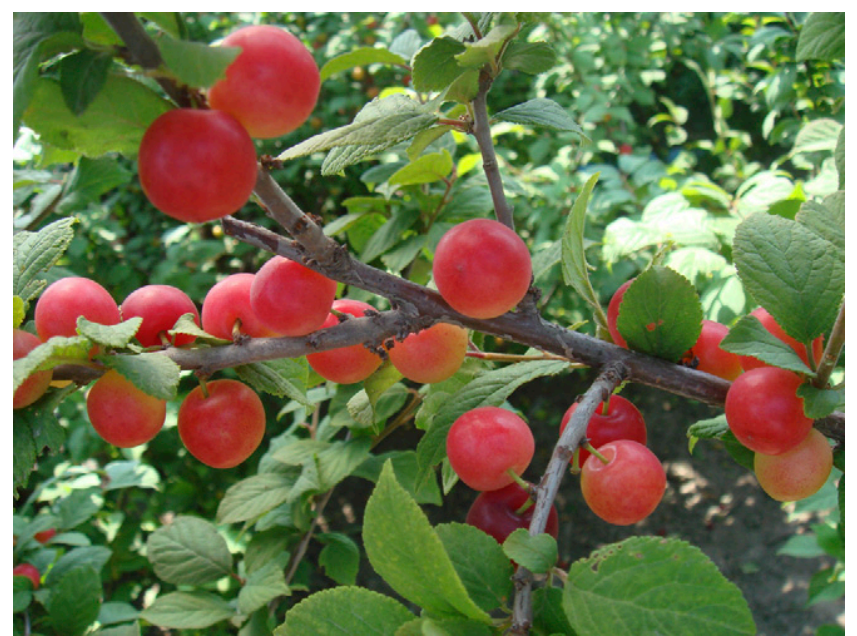

Fig. 3. Fruit on a hybrid tree.

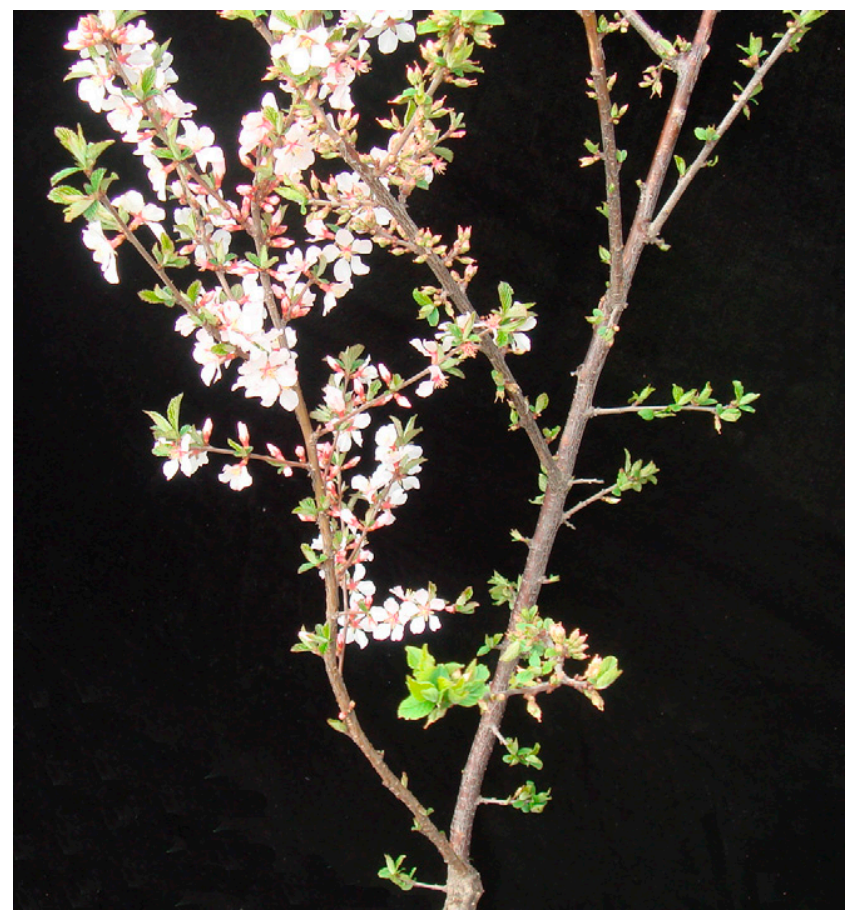

Fig. 4. Two-year-old hybrid seedling (right) grafted on P. tomentosa cherry (left). The hybrid flowers later than P. tomentosa. Both are compact and precocious.

yellow (RHS 20A) to light red (RHS 40D) near skin in fruit of $P$. salicina. Hybrid fruit was clingstone, similar to fruits of $P$. tomentosa and $P$. salicina. Hybrid fruit diameter ranged from 16 to $20 \mathrm{~mm}$, larger than $P$. tomentosa fruit (9-12 mm) (Fig. 2). The stone of the hybrid was round and similar to paternal parent $P$. salicina, while stones of $P$. tomentosa were characterized by flattened smooth surfaces. The characteristics of branches on the hybrid were intermediate between the two parents. Branch color was dark brown (RHS N200C), much darker than that of P. tomentosa (RHS 201B), but lighter than $P$. salicina (RHS N200B). The bark of the hybrid was smooth, similar to $P$. salicina but different from the scaley bark of $P$. tomentosa. Extent of branching was similar to $P$. salicina but lower than that of $P$. tomentosa, which was densely twiggy (Fig. 4). Internode length for the hybrid ranged from 20 to $30 \mathrm{~mm}$, similar to $P$. salicina $(20-35 \mathrm{~mm})$ but longer than P. tomentosa $(8-15 \mathrm{~mm})$.

Hybrid trees were compact, similar to $P$. tomentosa, both all considerably smaller than $P$. salicina. Hybrid trees were semispreading and had a main trunk similar to $P$. salicina, whereas $P$. tomentosa trees were shrub-like with multiple trunks.

Performance. Hybrid trees were grown in Heilongjiang, Jilin, and Liaoning provinces in the northeast of China (latitude $40^{\circ} 28^{\prime} \mathrm{N}$ to 


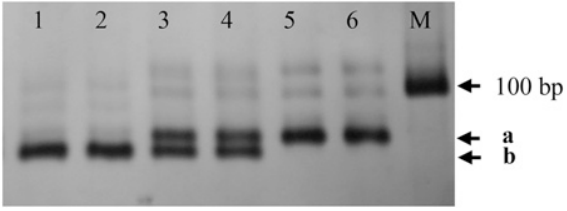

Fig. 5. Amplification products of the hybrid and both parents using SSR primer UDP96-003 Lanes 1-2: P. salicina accessions (Xiaobenli and Longyuanquli). Lanes 3-4: Interspecific hybrid. Lanes 5-6: P. tomentosa genotypes. $\mathrm{M}=$ DNA size marker. Allele " $\mathrm{a}$ " is a species specific band of $P$. tomentosa (original trees), allele " $b$ " is a species specific band of $P$. salicina accessions. The hybrid inherited both alleles "a" and " $b$ " from parents.

$47^{\circ} 24^{\prime} \mathrm{N}$; longitude $122^{\circ} 24^{\prime} \mathrm{E}$ to $127^{\circ} 58^{\prime} \mathrm{E}$ ) to evaluate performance. In these areas, the absolute minimum temperature in January ranges from $-30{ }^{\circ} \mathrm{C}$ to $-40{ }^{\circ} \mathrm{C}$ and it can reach $-45^{\circ} \mathrm{C}$ in extreme years (Liu et al., 2014). Fifty 2- to 3-year-old hybrid trees grafted onto $P$. tomentosa rootstock were evaluated for cold resistance respectively in Shanootgzhi County (Heilongjiang province), Changchun City (Jilin province), and Xiongyue Town (Liaoning province) in 2007-08. No cold injury was observed in flower buds, leaf buds, or branches after winters and trees grew well at all locations, which were representative of U.S. Department of Agriculture (USDA) hardiness zones $1 \mathrm{~b}$ and $2 \mathrm{a}$.

Phenology of the hybrid was similar to its parents. In Heilongjiang province, the hybrid flowering started at the beginning of May, 3-5 d later than $P$. tomentosa and the same time as $P$. salicina. Fruit ripened in mid-July, 15-20 d later than P. tomentosa and $10 \mathrm{~d}$ earlier than $P$. salicina (Fig. 4). Hybrid trees began to flower in the third growing season, similar to $P$. tomentosa, before $P$. salicina, which generally commences flowering in the fourth to fifth growing season. The hybrid was self-fertile.
The hybrid inherited disease-resistant characteristics from the maternal parent $P$. tomentosa. Bacteria shot hole disease (Xanthomonas arboricola pv. Prunis) (Smith, 1903) is a common disease in plum trees. None-pesticide treated hybrid trees growing close to plum orchards have not been observed to develop symptoms of bacteria shot hole disease on leaves, flowers, or fruit at all three evaluation sites.

Although the hybrid grew well on deep sandy soil, it showed adaptation to a wide range of soil types such as sandy, clay, loamy, or combinations of the three textures. The hybrid is being released primarily for fresh fruit consumption in cold climatic zones where only rare cold-resistant fruits can survive and produce fruit. It can potentially be of importance for future breeding efforts in Prunus.

Molecular confirmation. Extracted DNA of parents and hybrid was PCR-amplified using one pair of microsatellite primers UDP96-003 (forward: TTGCTCAAAAGTGTCGTTGC; reverse: ACACGTAGTGCAACACTGGC) developed by Cipriani et al. (1999). A distinct polymorphism was observed between parents at bands revealed 85 and 90 bps. Prunus salicina showed only the single $85 \mathrm{bps}$, while $P$. tomentosa showed only the $90 \mathrm{bps}$ (Zhang et al., 2008). The hybrid showed the both bands (Fig. 5), which confirmed that it is an interspecific hybrid between $P$. salicina and P. tomentosa.

Propagation and compatibility. Propagation of the hybrid can be achieved successfully by grafting soft or hard scion wood onto rootstocks of either $P$. tomentosa or $P$. salicina. June to July was the best time for T-budding and August was best for chipbudding. Branch-grafting using hardwood scions was also successful in April. The hybrid also proved graft compatible with most cultivars of $P$. salicina, $P$. persica, and $P$. armeniaca (Ingram, 1948; Rehder, 1940).

\section{Literature Cited}

Burbank, L. 1914. Luther Burbank: His methods and discoveries and their practical application. Vol. 4. Luther Burbank Press, New York.

Cipriani, G., G. Lot, W.G. Huang, M.T. Marrazzo, E. Peterlunger, and R. Testolin. 1999. AC/GT and $\mathrm{AG} / \mathrm{CT}$ microsatellite repeats in peach [Prunus persica (L) Batsch]: Isolation, characterization and cross-species amplification in Prunus. Theor. Appl. Genet. 99:65-72.

Felipe, A.J. 2009. 'Felinem', 'Garnem', and 'Monegro' Almond $\times$ Peach hybrid rootstocks. HortScience 44:196-197.

Gulcan, R. 1985. Descriptor list for almond (Amygdalus amygdalus). Revised Ed. International Board for Plant Genetic Resources, Rome.

Ingram, C. 1948. Ornamental cherries. Country Life, London.

Liu, H.J., X. Li, A.F. Jin, and C.J. Li. 2014 Variation of extreme temperature during the last 60 years in Shangzhi City. J. Agr. Sci. Yanbian Univ. 36(2):130-135 (in Chinese).

Rehder, A. 1940. Manual of cultivated trees and shrubs. 2nd ed. Macmillan, New York, pp. 452-481.

Royal Horticulture Society. 2007. Royal Horticulture Society colour chart. 5 th ed. Royal Hort. Soc., London, UK.

Shoferistov, E.P. 1988. Nectarine breeding in the Crimea. Acta Hort. 224:281-284 (ISHS).

Smith, E.F. 1903. Observation on a hitherto unreported bacterial disease, the cause of which enters the plant through ordinary stomata. Science 17:456-457.

Yü, T.T. and C.L. Li. 1986. Cerasus, p. 1-13. In: Yü, T.T. (ed.). Flora Reipublicae Popularis Sinicae 38. Science Press, Beijing (in Chinese).

Warner, G. 1998. Russian stone fruit roootstocks show promise. Good Fruit Grower 49(10):11.

Zhang, J.Y. 1990. Report on the investigation of national plum and apricot resources. China Fruits 4:29-34 (in Chinese).

Zhang, Q.J., G.J. Yan, H.Y. Dai, X.Z. Zhang, C.M. Li, and Z.H. Zhang. 2008. Characterization of Tomentosa cherry ( $P$. tomentosa Thunb.) genotypes using SSR markers and morphological traits. Sci. Hort. 118:39-47. 